Jurnal Matematika UNAND

Vol. 1 No. 2 Hal. $66-70$

ISSN : 2303-291X

(C)Jurusan Matematika FMIPA UNAND

\title{
SUATU BUKTI DARI WEDDERBURN'S LITTLE THEOREM
}

\author{
PUTRI ANGGRAYNI \\ Program Studi Matematika, \\ Fakultas Matematika dan Ilmu Pengetahuan Alam, Universitas Andalas Padang, \\ Kampus UNAND Limau Manis Padang, Indonesia \\ putri.anggrayni@gmail.com
}

\begin{abstract}
Abstrak. Dalam Wedderburn's Little Theorem dinyatakan bahwa setiap gelanggang pembagian yang mempunyai sejumlah berhingga unsur adalah komutatif, sehingga merupakan suatu lapangan. Teorema ini telah dibuktikan oleh banyak orang dengan berbagai ide berbeda. Dalam paper ini akan dikaji suatu bukti yang berdasarkan pada dua fakta mengenai lapangan berhingga.
\end{abstract}

Kata Kunci: Gelanggang pembagian, lapangan berhingga.

\section{Pendahuluan}

Gelanggang merupakan struktur penting dalam aljabar modern. Jika setiap unsur tak-nol dari suatu gelanggang $R$ membentuk grup terhadap operasi perkalian, maka $R$ disebut gelanggang pembagian (division ring). Dengan demikian satu hal yang hilang dari $R$ untuk menjadi suatu lapangan adalah komutatifitas terhadap perkalian.

Pada tahun 1905 seorang matematikawan Skotlandia, Joseph H. M. Wedderburn, membuktikan suatu teorema yang dinyatakan sebagai berikut: "Setiap gelanggang pembagian berhingga merupakan suatu lapangan". Teorema yang lebih dikenal sebagai Wedderburn's Little Theorem ini telah dibuktikan oleh banyak orang dengan berbagai ide berbeda. Wedderburn sendiri telah memberikan tiga buah bukti dari teorema ini pada 1905, dan bukti lainnya diberikan oleh Leonard E. Dickson pada tahun yang sama. Selanjutnya Emil Artin, Hans Zassenhaus, Nicolas Bourbaki, dan Ernst Will adalah nama-nama terkenal yang juga telah membuktikan teorema ini.

Dalam paper ini akan dikaji suatu bukti dari Wedderburn's Little Theorem yang berdasarkan pada dua fakta berikut, sebagaimana yang ditulis dalam [1]:

(1) Grup perkalian dari unsur-unsur tak-nol dari suatu lapangan berhingga adalah siklis [2].

(2) Jika $F$ adalah suatu lapangan berhingga dan $\alpha \neq 0, \beta \neq 0$ adalah dua buah unsur di $F$, maka terdapat unsur $a$ dan $b$ di $F$ sedemikian sehingga $1+\alpha a^{2}+$ $\beta b^{2}=0[2]$. 


\section{Wedderburn's Little Theorem pada Gelanggang Pembagian Berhingga}

Sebelum mengkaji bukti dari Wedderburn's Little Theorem, akan dibuktikan beberapa lema dan akibat berikut.

Lema 2.1. [1] Misalkan D adalah suatu gelanggang pembagian dengan karakteristik $p>0, Z(D)=\{z \in D \mid z x=x z, \forall x \in D\}$ adalah center dari $D$, dan $P$ adalah lapangan prima dengan $p$ unsur, dimana $P$ termuat di $Z(D)$. Andaikan $a \in D, a \notin$ $Z(D)$ sedemikian sehingga $a^{p^{n}}=a$ untuk suatu $n>0$, maka terdapat suatu $x \in D$ sedemikian sehingga

1. $x a x^{-1} \neq a$,

2. $x^{-1} \in P(a)$, lapangan yang diperoleh dengan menggandengkan a ke $P$.

Bukti. Didefinisikan suatu pemetaan $\delta_{a}: D \rightarrow D$ oleh $\delta_{a}(y)=y a-a y$ untuk semua $y \in D$. Karena a algebraic atas $P$, maka $P(a)$ merupakan suatu lapangan berhingga dan mempunyai $p^{m}$ unsur, untuk suatu bilangan bulat $m$. Semua unsur $P(a)$ memenuhi $u^{p^{m}}=u$. Melalui suatu pembuktian yang mudah, diperoleh bahwa $\delta_{a}^{p^{m}}(y)=y a^{p^{m}}-a^{p^{m}} y=y a-a y=\delta_{a}(y)$ untuk semua $y \in D$. Dengan demikian $\delta_{a}^{p^{m}}(y)=\delta_{a}(y)$.

Jika $\lambda \in P(a)$, maka $\delta_{a}(\lambda x)=(\lambda x) a-a(\lambda x)=\lambda(x a-a x)=\lambda \delta_{a}(x)$, karena $\lambda$ komutatif dengan $a$. Dengan demikian pemetaan $\lambda I: D \rightarrow D$, yang didefinisikan oleh $\lambda I(y)=\lambda y$, komutatif dengan $\delta_{a}$ untuk setiap $\lambda \in P(a)$. Karena setiap unsur $P(a)$ memenuhi polinomial $u^{p^{m}}-u$, maka $u^{p^{m}}-u=\left(u-\lambda_{1}\right)\left(u-\lambda_{2}\right) \cdots\left(u-\lambda_{p^{m}}\right)$, dimana $\lambda_{i}$ adalah $p^{m}$ unsur yang berbeda di $P(a)$. Dengan menggunakan fakta bahwa $\left(\lambda_{i} I\right) \circ \delta_{a}=\delta_{a} \circ\left(\lambda_{i} I\right)$ untuk semua $\lambda_{i} \in P(a)$, maka diperoleh

$$
0=\delta_{a}^{p^{m}}-\delta_{a}=\left(\delta_{a}-\lambda_{1} I\right) \circ\left(\delta_{a}-\lambda_{2} I\right) \circ \cdots \circ\left(\delta_{a}-\lambda_{p^{m}} I\right)
$$

dimana $\left(\delta_{a}-\lambda I\right)(x)=\delta_{a}(x)-\lambda x$.

Selanjutnya misalkan $\lambda_{1}=0$, dan andaikan untuk setiap $\lambda_{i} \neq 0$ diperoleh $\left(\delta_{a}-\lambda_{i} I\right) \neq 0, \forall y \neq 0 \in D ;$ maka

$$
\left[\left(\delta_{a}-\lambda_{2} I\right) \circ \cdots \circ\left(\delta_{a}-\lambda_{p^{m}} I\right)\right](x) \neq 0, \forall y \in D, x \neq 0 .
$$

Namun karena $0=\delta_{a}^{p^{m}}-\delta_{a}=\delta_{a} \circ\left(\delta_{a}-\lambda_{2} I\right) \circ \cdots \circ\left(\delta_{a}-\lambda_{p^{m}} I\right)$ maka diperoleh $\delta_{a}=0$, sehingga $0=\delta_{a}(y)=y a-a y$ mengakibatkan $a \in Z(D)$. Hal ini bertentangan dengan hipotesa bahwa $a \notin Z(D)$. Dengan demikian, terdapat suatu $\lambda \neq 0$ di $P(a)$ dan suatu $x \neq 0$ di $D$ sedemikian sehingga $\left(\delta_{a}-\lambda I\right)(x)=0$, yaitu $x a-a x-\lambda x=0$. Karena $\lambda \neq 0$, maka $x a x^{-1}=a+\lambda \neq a$, dan karena $\lambda \in P(a)$, maka $x a x^{-1} \in P(a$.

Lema di atas memberikan akibat berikut ini.

Akibat 2.2. [1] $x a x^{-1}=a^{i} \neq a$ untuk suatu bilangan bulat $i$.

Bukti. Misalkan $a$ berorde $s$, maka semua akar dari polinomial $u^{s}-1$ di lapangan $P(a)$ adalah $1, a, a^{2}, \cdots, a^{s-1}$. Karena $\left(x a x^{-1}\right)^{s}=x a^{s} x^{-1}=1$, dan karena $x a x^{-1} \in$ $P(a)$, dengan $x a x^{-1}$ adalah suatu akar dari $u^{s}-1$ di $P(a)$, maka $x a x^{-1}=a^{i}$. 
Lema 2.3. [2] Misalkan D adalah suatu gelanggang pembagian berhingga sedemikian sehingga setiap subgelanggang pembagian sejatinya adalah komutatif. Misalkan $a, b \in D$ memenuhi $a b \neq b a$ tetapi $b^{t} a=a b^{t}$, untuk suatu bilangan bulat $t, \operatorname{maka} b^{t} \in Z(D)$.

Bukti. Misalkan himpunan $N_{D}\left(b^{t}\right)=\left\{x \in D \mid x b^{t}=b^{t} x\right\} . N_{D}\left(b^{t}\right)$ merupakan suatu subgelanggang pembagian dari $D$. Jika $N_{D}\left(b^{t}\right) \neq D$, maka berdasarkan hipotesa, $N_{D}\left(b^{t}\right)$ adalah komutatif. Namun $a, b \in N_{D}\left(b^{t}\right)$ dan $a b \neq b a$; akibatnya $N_{D}\left(b^{t}\right)$ tidak komutatif dan haruslah $N_{D}\left(b^{t}\right)=D$. Dengan demikian $b^{t} \in Z(D)$.

Lema 2.4. [2] Jika $y \in D$ sedemikian sehingga $y^{r}=1$, maka $y=\lambda^{i}$.

Bukti. Perhatikan lapangan $C(y)=\{c \in D \mid c y=y c\}$ yang merupakan perluasan dari $Z(D)$. Karena $r$ adalah prima, maka unsur-unsur $\lambda^{0}, \lambda^{1}, \lambda^{2}, \cdots, \lambda^{r-1} \in Z(D)$ semua berbeda dan memenuhi $\lambda^{i} y=y \lambda^{i}$. Oleh karena itu $\lambda^{i} \in C(y), i=$ $0,1, \cdots, r-1$. Perhatikan bahwa polinomial $p(y)=y^{r}-1$ berada di lapangan $Z(D)$ dan $\lambda^{i} \in C(y), i=0,1, \cdots, r-1$ mengakibatkan $p\left(\lambda^{i}\right)=0$. Karena polinomial $p(y)$ memiliki paling banyak $r$ akar di lapangan $C(y)$, maka jelaslah bahwa $y=\lambda^{i}, i=0,1, \cdots, r-1$. Dengan demikian, $y \in Z(D)$.

Lema 2.5. [3] Misalkan $D$ adalah suatu gelanggang pembagian berhingga dengan char $D \neq 2$ dan andaikan terdapat $a_{1}, b_{1} \in D$ sedemikian sehingga

1. $a_{1} b_{1}=-b_{1} a_{1} \neq b_{1} a_{1}$;

2. $a_{1}^{2}=b_{1}^{2}=\alpha \neq 0$;

3. terdapat suatu $\xi, \eta \in Z(D)$ sedemikian sehingga $1+\xi^{2}-\alpha \eta^{2}=0$;

maka $a_{1}+\xi b_{1}+\eta a_{1} b_{1}=0$.

Bukti. Perhatikan bahwa $\left(a_{1}+\xi b_{1}+\eta a_{1} b_{1}\right)^{2}=a_{1}^{2}+\xi^{2} b_{1}^{2}+\eta^{2} a_{1} b_{1} a_{1} b_{1}+\xi a_{1} b_{1}+$ $\xi b_{1} a_{1}+\eta a_{1}^{2} b_{1}+\eta a_{1} b_{1} a_{1}+\xi \eta b_{1} a_{1} b_{1}+\xi \eta a_{1} b_{1}^{2}=\alpha+\xi^{2} \alpha+\eta^{2}\left[a_{1}\left(-a_{1} b_{1}\right) b_{1}\right]=\alpha[1+$ $\left.\xi^{2}-\alpha \eta^{2}\right]=0$.

Karena $D$ adalah suatu gelanggang pembagian, maka $a_{1}+\xi b_{1}+\eta a_{1} b_{1}=0$.

Berikut adalah hasil utama dari paper ini.

Teorema 2.6. [1] Setiap gelanggang pembagian berhingga merupakan suatu lapangan.

Bukti. Misalkan $D$ adalah suatu gelanggang pembagian berhingga dan $Z(D)$ adalah center dari $D$. Jika teorema tidak benar untuk semua gelanggang pembagian berhingga $D$, maka $D$ dipilih sedemikian sehingga $D$ memiliki orde minimal di antara gelanggang-gelanggang pembagian non-komutatif. Dengan demikian, setiap gelanggang pembagian berhingga dengan orde kurang dari orde $D$ adalah komutatif. Akan ditunjukkan bahwa asumsi mengenai gelanggang $D$ ini akan menuju pada suatu kontradiksi.

Setiap unsur taknol di $D$ mempunyai orde berhingga, sehingga beberapa pangkat positif dari unsur-unsur taknol tersebut berada di $Z(D)$. Misalkan $w \in D$, maka 
orde dari $w$ yang relatif ke $Z(D)$ adalah bilangan bulat positif terkecil $m(w)$ sedemikian sehingga $w^{m(w)} \in Z(D)$.

Pilih suatu unsur $a \in D, a \notin Z(D)$ yang memiliki orde minimal yang tepat relatif ke $Z$, dan misalkan orde ini adalah $r$. Diklaim bahwa $r$ adalah suatu bilangan prima. Berdasarkan Akibat 2, terdapat suatu $x \in D$ sedemikian sehingga $x a x^{-1}=a^{i} \neq a$, untuk suatu $i \in \mathbb{Z}$. Karena $r$ adalah bilangan prima, dengan menggunakan Fermat's Little Theorem [4], diperoleh $x^{r-1} a x^{-(r-1)}=a^{i^{r-1}}=a^{1+r u}=a a^{r u}=\lambda a$ dimana $\lambda=a^{r u} \in Z(D)$. Dengan demikian, $x^{r-1} a=\lambda a x^{r-1}$. Karena $x \notin Z(D)$ dan berdasarkan sifat minimal $r$, diperoleh $x^{r-1} \notin Z(D)$. Hal ini mengakibatkan $\lambda \neq 1$.

Selanjutnya misalkan $b=x^{r-1}$; dengan demikian $b a b^{-1}=\lambda a$; akibatnya $\lambda^{r} a^{r}=$ $(\lambda a)^{r}=\left(b a b^{-1}\right)^{r}=b a^{r} b^{-1}=a^{r}$ karena $a^{r} \in Z(D)$. Hal ini mengakibatkan $\lambda^{r}=1$. Karena $\lambda^{r}=1$, maka $b^{r}=\lambda^{r} b^{r}=(\lambda b)^{r}=\left(a^{-1} b a\right)^{r}=a^{-1} b^{r} a$, sehingga $a b^{r}=b^{r} a$. Karena $a b^{r}=b^{r} a$ dan $a b \neq b a$ maka berdasarkan Lema 3 diperoleh $b^{r} \in Z(D)$.

Grup perkalian dari unsur-unsur tak nol $Z(D)$ adalah siklis dan dibangun oleh suatu unsur $\gamma \in Z(D)$. Dengan demikian $a^{r}=\gamma^{n}, b^{r}=\gamma^{m}$, untuk suatu bilangan bulat $n$ dan $m$. Jika $n=k r$, dengan $k$ adalah suatu bilangan bulat, maka $\left(\frac{a}{\gamma^{k}}\right)^{r}=1$, sehingga berdasarkan Lema 4 diperoleh $\frac{a}{\gamma^{k}}=\lambda^{i}$. Oleh sebab itu $a \in Z(D)$. Hal ini bertentangan dengan $a \notin Z(D)$. Dengan demikian $r \nmid n$, dan dengan cara yang sama $r \nmid m$.

Selanjutnya misalkan $a_{1}=a^{m}$ dan $b_{1}=b^{n}$, maka $a_{1}^{r}=a^{r m}=\gamma^{n m}=b^{r n}=b_{1}^{r}$ sehingga diperoleh

$$
a_{1}^{r}=b_{1}^{r}=\alpha \in Z(D) .
$$

Kemudian karena $b a=\lambda a b$ maka $b=\lambda a b a^{-1}$. Oleh karena itu $b^{n}=\lambda^{n}\left(a b a^{-1}\right)^{n}=$ $\lambda^{n} a b^{n} a^{-1}$, dan $b^{n} a=\lambda^{n} a b^{n}$ sehingga $a=\lambda^{n} b^{-n} a b^{n}$. Hal ini mengakibatkan $a^{m}=\lambda^{m n}\left(b^{-n} a b^{n}\right)^{m}=\lambda^{m n} b^{-n} a^{m} b^{n}$ sehingga $b^{n} a^{m}=\lambda^{m n} a^{m} b^{n}$. Dengan demikian diperoleh

$$
b_{1} a_{1}=\mu a_{1} b_{1}, \mu=\lambda^{m n} \in Z(D) .
$$

Karena $\lambda^{r}=1$ dan $r$ tidak membagi $m$ maupun $n$, maka $\mu \neq 1$, tetapi $\mu^{r}=1$.

Melalui perhitungan sederhana menggunakan (1), akan diperoleh

$$
\left(b_{1}^{-1} a_{1}\right)^{r}=\mu^{1+2+\cdots+(r-1)} b_{1}^{-r} a_{1}^{r}=\mu^{r(r-1) / 2} .
$$

Jika $r$ adalah bilangan prima ganjil, maka $\left(b_{1}^{-1} a_{1}\right)^{r}=1$. Oleh sebab itu, berdasarkan Lema $4, b_{1}^{-1} a_{1}=\lambda^{i} \in Z(D)$ sehingga $a_{1}=\lambda^{i} b_{1}$. Perhatikan bahwa $b_{1} a_{1}=$ $b_{1}\left(\lambda^{i} b_{1}\right)=\left(\lambda^{i} b_{1}\right) b_{1}=a_{1} b_{1}$. Hal ini berkontradiksi dengan $b_{1} a_{1}=\mu a_{1} b_{1}, \mu \neq 1$. Dengan demikian, teorema terbukti jika $r$ merupakan bilangan prima ganjil.

Jika $r=2$, maka diperoleh dua unsur $a_{1}^{2}=b_{1}^{2}=\alpha \in Z(D)$ dan $\mu=-1$, karena $\mu^{2}=1, \mu \neq 1$. Dengan demikian $b_{1} a_{1}=-a_{1} b_{1} \neq a_{1} b_{1}$; sebagai konsekuensi, karakteristik $D$ bukanlah 2. Selanjutnya, karena $Z(D)$ adalah suatu lapangan berhingga dan $a_{1}^{2}=b_{1}^{2}=\alpha \neq 0 \in Z(D)$, maka terdapat unsur $\xi, \eta \in Z(D)$ sedemikian sehingga $1+\xi^{2}-\alpha \eta^{2}=0$. Berdasarkan Lema 5 diperoleh bahwa $a_{1}+\xi b_{1}+\eta a_{1} b_{1}=0$. Namun

$$
0=a_{1}\left(a_{1}+\xi b_{1}+\eta a_{1} b_{1}\right)+\left(a_{1}+\xi b_{1}+\eta a_{1} b_{1}\right) a_{1}=2 a_{1}^{2}=2 \alpha \neq 0 .
$$


Karena $0 \neq 0$ adalah hal yang mustahil, maka kontradiksi ini mengakhiri bukti dari Wedderburn's Little Theorem.

\section{Ucapan Terima kasih}

Penulis mengucapkan terima kasih kepada Bapak Admi Nazra, Ibu Lyra Yulianti, Bapak Muhafzan, dan Bapak Ahmad Iqbal Baqi yang telah memberikan masukan dan saran sehingga paper ini dapat diselesaikan dengan baik.

\section{Daftar Pustaka}

[1] Herstein, I. N. 1961. Wedderburn's theorem and a theorem of Jacobson. The American Mathematical Monthly. Vol. 68, No.3, hal. 249-251

[2] Herstein, I. N. 1999. Topics in Algebra. Second Edition. John Wiley and Sons, New York

[3] Paley, H. dan P. M. Weichsel. 1966. A First Course in Abstract Algebra. Holt, Rinehalt and Winston Inc, New York

[4] Rosen, K. H. 2005. Elementary Number Theory and Its Applications. Fifth Edition. Pearson, Addison Wesley, Boston 